\title{
Highly Sensitive Electrochemical Sensor based on Carbon Dots Reduced Gold Nanoparticles for Ractopamine Detection in Pork Meat
}

\author{
Chengcheng Song ${ }^{1}$, Qinghe Wei ${ }^{1}$, Hong $\mathrm{Li}^{3,4,5, *}$, Hongmei Gao ${ }^{1, *}$, Jiping An ${ }^{2, *}$ andBin $Q i^{1, *}$ \\ ${ }^{1}$ Faculty of Chemistry, Northeast Normal University, Changchun, 130024, China \\ ${ }^{2}$ Hospital of Stomatology, Jilin University, Changchun, 130024, China \\ ${ }^{3}$ Key Laboratory of Narcotics Assay and Control Technology, Ministry of Public Security \\ ${ }^{4}$ Public Security Department of Yunnan Province, Kunming, 650220, China \\ ${ }^{5}$ Institute of Forensic Science, Ministry of Public Security, P. R. China \\ *E-mail: qib219@nenu.edu.cn
}

doi: $10.20964 / 2020.04 .07$

Received: 29 November 2019/ Accepted: 31 January 2020 / Published: 10 March 2020

\begin{abstract}
A microwave synthesis process was used to successfully prepare carbon dots (CDs). Then the prepared carbon dots were employed as reductants to prepare gold nanoparticles. The kinetic characteristics of CDs@Au/GCE, the electrochemical behaviour of ractopamine (Rac) on CDs@Au/GCE and the electrochemical determination of Rac were investigated. Electrochemical characterization results show that the prepared gold nanoparticles can be used as a stable modification on the surface of a glassy carbon electrode (GCE). Differential pulse voltammetry (DPV) results show that within a range of 0.01 to 32.5 $\mathrm{mg} / \mathrm{L}$, the linear correlation coefficient of the response current to the Rac concentration is 0.9999 , furthermore, the detection limit is $1.2 \mu \mathrm{g} / \mathrm{L}$, which is lower than previous report $(1.5 \mu \mathrm{g} / \mathrm{L})$. The electrochemical sensors for Rac were developed using CDs to reduce gold nanoparticles. The above sensor have high sensitivity and good reproducibility and stability, thus, they show potential applications for Rac analysis.
\end{abstract}

Keywords: carbon dots, gold nanoparticles, ractopamine, electrochemical sensors, microwave synthesis

\section{FULL TEXT}

(C) 2020 The Authors. Published by ESG (www.electrochemsci.org). This article is an open access article distributed under the terms and conditions of the Creative Commons Attribution license (http://creativecommons.org/licenses/by/4.0/). 